\title{
Microprocessor-assisted assessment in the clinical research laboratory
}

\author{
ROBERT F. BREMSER and ROBERT S. DAVIDSON \\ Veterans Administration Hospital, Miami, Florida 33125
}

\begin{abstract}
The application of microprocessor technology to assessment of alcoholism in a clinical research laboratory is described.
\end{abstract}

Several recent reviews and articles (Martin \& Conner, 1975; Schneider \& Scholz, 1973; Shure \& Meeker, 1970) have indicated the utility of computer-based systems of control in experimental laboratories. There is also a growing literature describing the use of fullsize and minicomputers in medical and psychiatric assessment batteries (Angle, Hay, Hay, \& Ellinwood, 1977; Greist, Klein, \& Van Cura, 1973; Kleinmuntz, 1972; Maultsby \& Slack, 1971; Mayne, Weksel, \& Sholtz, 1968; Slack \& Van Cura, 1968). The purpose of this paper is to describe the application of a microprocessor to the problem of assessment in the clinical research laboratory.

\section{CLINICAL (PAPER AND PENCIL) ASSESSMENT FORMAT AND PROCEDURES}

An assessment battery is presented to all patients referred by physicians for the purpose of evaluating eligibility and obtaining consent to participate in a behavioral research and treatment program in alcoholism (Davidson, 1974). Consenting patients who live near the facility are given behavior modification forms of treatment, including relaxation, assertiveness training, aversive conditioning, covert sensitization, verbal conditioning, moderation training, or behavior therapy. The assessment battery, derived from several sources (Davidson, 1974), includes 65 items in demographic, family inistory, drinking history, drinking rate and pattern, drinking antecedents and consequences, symptoms, and occupational, social, family, and psychological adjustment areas.

The battery is usually administered verbally by a psychologist or technician and contains mostly multiplechoice items. Some items require a numerical estimate (e.g., age, years of education, number of years drinking has been a problem); others require verbal responses (e.g., "What is the main reason you drink?" and "What led up to your last long period of abstinence?").

The program reported here was supported by Veterans Administration Research Project 1777-01, Modification of Alcoholic Behavior, Robert S. Davidson, principal investigator. Reprints may be requested from Robert F. Bremser, Research Service (151) Veterans Administration Hospital, 1201 N.W. 16th Street, Miami, Florida 33125.
A recent computerized statistical analysis (discriminant function) of these items revealed that 12 of them could be used to predict, with greater than $90 \%$ accuracy, the success or failure of a form of behavior modification for alcoholic behavior at 6-month follow-up (Davidson, Mortensen, Bremser, Sayles, \& Greenwald, Note 1). The 30 subjects in this study received aversive conditioning over a 4- to 6-week inpatient treatment period, after which they were invited to return for six follow-up visits over 6 months. Successful outcomes were defined by corroborated abstinence or occasional drinking at less than intoxicating levels (usually less than $4 \mathrm{oz}$ absolute alcohol equivalent per day). Failure was defined by corroborated frequent intoxication, including periodic or binge drinking and uncontrolled frequent heavy drinking. Items predictive of outcome (in order of probability) were birth order, living arrangements prior to treatment, number of siblings, previous blackouts, mother died in patient's childhood, age, number of children, whether the spouse got angry at patient's drinking, whether father died in patient's childhood, number of prior court convictions, prior hospitalizations, and whether the father was a heavy drinker. Surprisingly, 8 of these 12 variables were demographic or familial and only 4 were related to prior symptoms, drinking history, or prior treatment.

Since all of our patients must be delivered a great deal of information regarding the confidentiality of the interview and the voluntary nature of the study, for which they must give informed consent, in addition to the assessment, a great deal of professional staff time can be saved by collecting and delivering this information via computer.

The following, then, describes the instrumentation and software selected for the purpose of computerizing our assessment. A brief description of the computer program is also described.

\section{INSTRUMENTATION}

Our orientation, program direction, and budget called for a microcomputer system that offered: (1) the capability of mass storage and retrieval of data and programs; (2) flexibility of use as a stand-alone computer and an intelligent interactive terminal; (3) the 
simplicity and economy of a system with the fewest units to be added (e.g., separate keyboard, central processing unit, cathode-ray tube monitor, etc.); and (4) compatibility with the proliferating number of peripherals available on the $\mathrm{S}-100$ bus.

The Sol terminal computer (Processor Technology) meets most of our needs. It offers the convenience of single-board construction with all the support circuitry for every one of the 8080 microprocessor (40-pin integrated circuit chip) functions. It also has circuitry for: (1) parallel and serial input-output (I/O) ports with full-control handshaking and a switch-selectable baud rate of $75-9,600 ;(2)$ interface for direct connection of two audio cassette recorders for data storage; (3) complete keyboard encoding with keyboard separately attached to main frame of unit; (4) direct connections for video monitor, including $1 \mathrm{~K}(1,024$ 8-bit words) of display memory; (5) a 128 upper- and lowercase alphanumeric character generator with the ASCII control character set included; (6) up to $2 \mathrm{~K}$ of read-only memory (ROM) on a plug-in module for the operating system; (7) $1 \mathrm{~K}$ static random-access memory (RAM) for user-defined $\mathrm{I} / \mathrm{O}$ routines; and (8) addressing to $65 \mathrm{~K}(65,455$ 8-bit words).

The Sol is packaged in a small, sturdy, typewritershaped case. Processor Technology offers a variety of system packages, assembled or in kit form, ranging in price from a few hundred to several thousand dollars.

Two disk drive units and floppy-disk control board (North Star) have been added in preference to cassette recorders. The disk control units provide an additional 90K accessible memory per disk. These are much more convenient in terms of general utility and shelf storage space than tapes of any kind, which are often slower and do not always allow random access.

Hard copies of all programs, output, and data are available through a printer (OKIdata 110) with tractor feed and RS-232 interface. This printer has a throughput of 65 lines/min at selectable baud rates, which makes it compatible with most systems, as well as fast and efficient.

Finally, the addition of a CRT monitor (Sanyo VM-4209) ${ }^{1}$ provides a visual scan and readout of any programming and assessment items. The monitor is an essential part of the system, in terms of providing feedback on software development, facilitating on-line programming and program modification, and presenting assessment items to patients.

\section{SOFTWARE}

Our assessment battery was developed on an extended version of BASIC, provided by North Star for use with their disk operating system (DOS). Both the DOS and the extended BASIC are provided on a 5 -in. microfloppy diskette. BASIC was selected over other available languages because it was designed for ease of human interactional programming, is easy to learn, bears a close resemblance to English, lends itself readily to manipulation of strings or lists of alphanumeric characters, and is an interactive language that will request and wait for an input (e.g., a response to an assessment item). North Star BASIC requires at least a $16 \mathrm{~K}$ RAM system and is generally released for a $16 \mathrm{~K}$ system, but can easily be made compatible with larger systems by changing 1 byte of program memory.

Our system has $40 \mathrm{~K}$ continuous RAM beginning at zero. DOS begins at 2,000 hex and BASIC is loaded above DOS at $2 \mathrm{~A} 00$ hex. This leaves $8 \mathrm{~K}$, from 0 to $1 \mathrm{FFF}$, unused. Although this $8 \mathrm{~K}$ can be readdressed to start at the end of the last byte of system RAM, we have chosen to leave this memory available for machinelevel programs that can then be accessed by BASIC for execution.

Since BASIC and DOS together require $12 \mathrm{~K}$ of RAM and $8 \mathrm{~K}$ below DOS is unused, the total memory remaining available for programs written in BASIC is $20 \mathrm{~K}$. The assessment program in BASIC, if run continuously, utilizes altogether approximately $46 \mathrm{~K}$ of memory. Hence, the program is written, filed, loaded, and executed in three separate parts, since insufficient RAM is available to run the entire program continuously. The first part, "INTAKE," needs approximately $18 \mathrm{~K}$ to run; the second, "PART-2," also needs approximately $18 \mathrm{~K}$; the third part, "PRINT," needs approximately $10 \mathrm{~K}$ to run.

Automatic execution of each part is accomplished by the chain command (e.g., CHAIN "PART-2"). Prior to the chain command, all important variables are saved in a data file labeled simply "DATA" and then reaccessed after the execution of the next program in the chain.

The output is a hard-copy printout of a summary of all the patient input, with the exception of those questions answered in the negative or in compliance with the norm; for example,

Question: "Did your father die before you were
16 years old?"
Response: "No" (This response would not be printed.)
"Yes" (Then "**Father died prior to 16th
year" is printed.)

Thus, the overall length of the printout depends on the patient's answers.

The instrumentation and software have produced a truly interactive system, in which branching logic can be easily programmed, and responses to redundant or systematically replicated items can be compared for direct estimates of reliability. The storage of patient data generated in a file that can be accessed at any future time for identification, statistical analysis, cross reference, and outcome studies is being implemented.

\section{MICROCOMPUTER ASSESSMENT PROGRAM ${ }^{2}$}

The development of the coimputer program that 
administered the assessment battery required several modifications of some of the original items. For example, the item:

"How much of each of the kinds of alcohol listed below have you drunk each day in the month prior to admission (list in ounces)? (Use and/or to indicate concurrent vs. alternating patterns, e.g., gin and rum, gin or rum.)

\begin{tabular}{|c|c|c|}
\hline $\begin{array}{c}\text { Last } \\
2 \\
\text { years }\end{array}$ & $\begin{array}{l}\text { Month } \\
\text { prior to } \\
\text { admis- } \\
\text { sion }\end{array}$ & \\
\hline :__ : & :__: & whiskies (bourbon__, rye _, blend __ \\
\hline : & :__ : & scotch \\
\hline :__ & :__: & vodka \\
\hline :__: & :__: & gin \\
\hline :__: & :___: & rum \\
\hline : & :_ & wine (what kind? ___ \\
\hline :____ & :__ : & $\begin{array}{l}\text { liqueurs (like creme du menthe, } \\
\text { Drambuie, etc.)" }\end{array}$ \\
\hline
\end{tabular}

could not be programmed as is because of the number of implied questions, as well as detail required.

This particular item required a minimum of 10 separate computer-program questions for a single beverage drinker and as many as 50 or 60 for multiple beverage drinkers. Altogether, the microcomputer program has yielded a maximum length of about 200 items, not all of which may be used, depending on the responses of the patient (e.g., a patient reporting abstinence would be exposed to only about $50 \%$ of the total pool of items, while one reporting a complex combination of many types of beverage would respond to many more items).

Although the simplest use of the computer in assessment is to administer multiple-choice items (Angle et al., 1977), our patients, after a short introduction to the keyboard and CRT, appear fascinated with the messages sent and received through the system and demonstrate the ability to respond to more complex items. Although most of the items are multiple choice in format, several require numerical response (e.g., social security number, age, or number of ounces of a particular beverage consumed). Others require a "spelled-out" response (e.g., name, or a typed explanation in response to the selection of "other" in some multiple-choice questions).

Enough patients have been exposed to the computerized assessment at this time to support the findings of other investigators that such use is not only possible, but perhaps even preferable over human administration to some patients (Angle et al., 1977; Slack \& Van Cura, 1968). Clearly, the bias in human administration associated with personality and nonverbal behavior is removed.

\section{REFERENCE NOTE}

1. Davidson, R. S., Mortensen, R. M., Bremser, R. F., Sayles, T. S., \& Greenwald, S. Predictors of success in aversive modifi. cation of alcoholism. Unpublished manuscript.

\section{REFERENCES}

Angle, H. V., Hay, L. R., Hay, W. M., \& Ellinwood, E. H. Computer assisted behavioral assessment. In J. D. Cone \& R. P. Hawkins (Eds.), Behavioral assessment. New York: Brunner/Mazel, 1977.

Davidson, R. S. Alcoholism: Experimental analyses of etiology and modification. In K. S. Calhoun, H. E. Adams, \& K. M. Mitchell (Eds.), Innovative treatment methods in psychopathology. New York: John Wiley, 1974.

Greist, J. H., Klein, M. H., \& Van Cura, L. J. A computer interview for psychiatric patient target symptons. Archives of General Psychiatry, 1973, 29, 247-253.

KLEINMuntz, B. Computers in personality assessment. In B. Kleinmuntz (Ed.), Computers in personality assessment. Morristown, N.J: General Learning Press, 1972. Pp. 1-22.

Martin, R. A., \& Conner, R. J. Computer control for operant oriented laboratories. Behavior Research Methods \& Instrumentation, 1975, 7, 151-156.

Maultsby, M. C., \& Slack, W. V. A computer-based psychiatry history system. Archives of General Psychiatry, 1971, 25, 570-572.

Mayne, J. G., Weksel, W., \& Sholtz, P. N. Toward automating the medical history. Mayo Clinic Proceedings, $1968,43,1-25$.

SchneIder, W., \& Scholz, K. W. Requirements for minicomputer operating systems for human experimentation and an implementation on a $4 \mathrm{~K}$ PDP-8 computer. Behavior Research Methods \& Instrumentation, 1973, 5, 173-177.

SHURE, G. H., \& MeEKer, R. J. A computer-based experimental laboratory. American Psychologist, 1970, 25, 962-969.

Slack, W. V., \& Van Cura, L. J. Patient reaction to computerbased medical interviewing. Computers and Biomedical Research, 1968, 1, 527.531.

\section{NOTES}

1. Although the system in current use depends upon one CRT monitor, plans are being implemented for a multiuser BASIC that will allow the use of several CRT terminals concurrently.

2. A hard-copy program run, using fictitious input, can be provided upon written request.

(Received for publication May 24, 1978; revision accepted June 28,1978 .) 